\title{
Invited Paper \\ RESEARCHES AND IMPLEMENTATIONS \\ OF STRUCTURAL HEALTH MONITORING SYSTEMS \\ FOR LONG SPAN BRIDGES IN CHINA
}

\author{
Limin $\mathrm{SUN}^{1}$, Zhi SUN ${ }^{2}$, Danhui DAN ${ }^{3}$, Qiwei ZHANG ${ }^{4}$ and Hongwei HUANG \\ ${ }^{1}$ Professor, State Key Laborotary for Disaster Reduction in Civil Engineering, Tongji University \\ (1239 Siping Rd., Shanghai 200092, China) \\ E-mail: lmsun@tongji.edu.cn \\ ${ }^{2}$ Associate Professor, State Key Laborotary for Disaster Reduction in Civil Engineering, Tongji University \\ (1239 Siping Rd., Shanghai 200092, China) \\ E-mail: sunzhi1@tongji.edu.cn \\ ${ }^{3}$ Associate Professor, State Key Laborotary for Disaster Reduction in Civil Engineering, Tongji University \\ (1239 Siping Rd., Shanghai 200092, Chnia) \\ E-mail: dandanhui@tongji.edu.cn \\ ${ }^{4}$ Professor, State Key Laborotary for Disaster Reduction in Civil Engineering, Tongji University \\ (1239 Siping Rd., Shanghai 200092, China) \\ E-mail: zhangqw@tongji.edu.cn \\ ${ }^{5}$ Lecturer, State Key Laborotary for Disaster Reduction in Civil Engineering, Tongji University \\ (1239 Siping Rd., Shanghai 200092, China) \\ E-mail: hongweih@tongji.edu.cn
}

Key Words: structural health monitoring, long span bridge, research and implementation, review

\begin{abstract}
This paper presents the recent development in the research and implementation of structural health monitoring systems for long span bridges in China. Following a brief review on the long span bridge projects in recent years and main deterioration and defects problems of existing bridges, the paper puts the focus on the review of the following three aspects: the implementation of structural health monitoring system for long span bridges, the advanced sensing, transmission, and system integration technologies, and the novel signal processing and condition assessment techniques. Finally, the issues on the future research and implementation of structural health monitoring system are discussed.
\end{abstract}

\section{INTRODUCTION}

In recent years, number of long span bridges are completed or under construction in the mainland and Hongkong of China. Many of these bridges have been installed with structural health monitoring systems (SHMS). This paper reviews recent research and implementation of SHMS for long span bridges in China.

\section{(1) Long span bridge projects in recent years ${ }^{1), 2 \text { ) }}$}

In 1980's, as a preparation stage, number of cablestayed bridges with span length less than $300 \mathrm{~m}$ were built in China. At the beginning of 1990's, Nanpu Bridge in Shanghai (Fig. 1) became a milestone, it brought a high tide of building long span bridges in China. Until the completion of Runyang Bridge (S) over Yangtze River (Fig. 2) in 2004, with a main span of $1490 \mathrm{~m}$, more than 100 long span bridges have been constructed in China. Table 1, Table 2 and Table 3 list the long span ( $>400 \mathrm{~m}$ ) cable-stayed

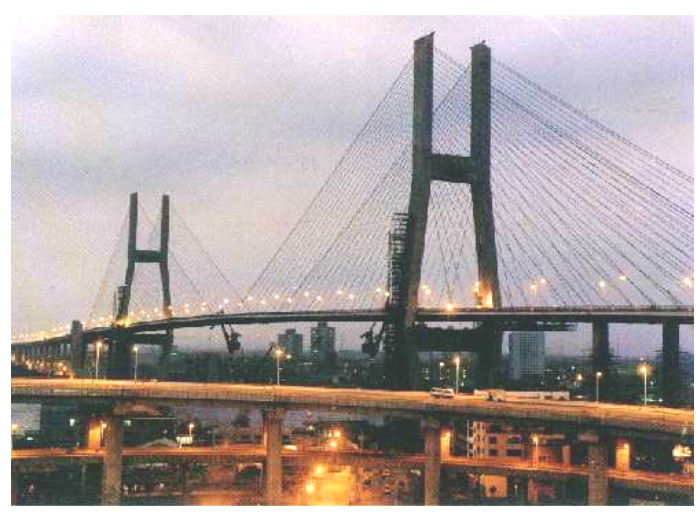

Fig.1 Nanpu Bridge in Shanghai (1990).

bridges, suspension bridges and arch bridges (Fig. 3) recently completed or under construction in China.

\section{(2) Operation conditions of bridges}

The importance of operation condition, namely the safety, durability and serviceability of long span 


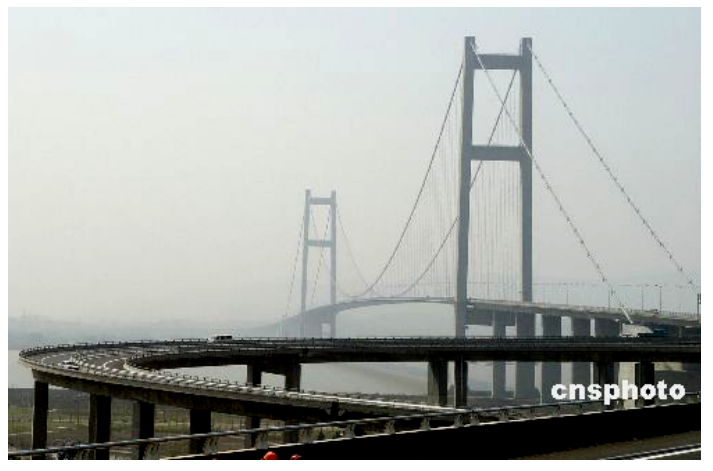

Fig.2 Runyang Bridge (S) over Yangtze River (2004).

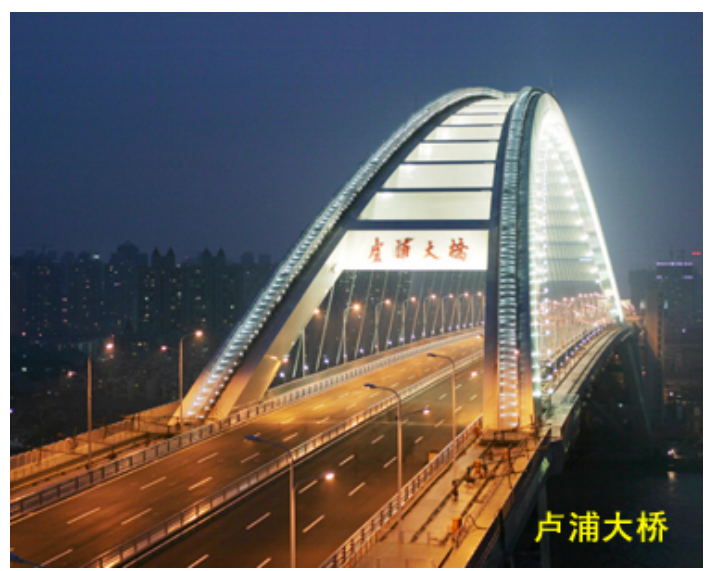

Fig.3 Lupu Bridge in Shanghai (2004).

bridges in China has drawn the attention of bridge management authorities and engineers. The research group of Tongji University has been carrying out field inspections on several bridges with the support of the China National Council of Science and Technology ${ }^{3)}$, and has discovered some problems related to the deterioration and defects of existing bridges in the following 3 aspects:

\section{a) Corrosion and rupture of steel wires in stay cables or PC cables}

Steel wires of cable strands were corroded or even ruptured in some cable-stayed bridges. The most serious case of steel wire rupture is Haiyin Bridge in Guangzhou ${ }^{4}$, where one of the stay cables broke suddenly in 1995 (Fig. 4). Another accident was the fall down of the center span of Tian Zuang Tai Bridge ${ }^{5)}$ in Liaoning Province in 2004 due to the broken of PC tendons even though the bridge span is short (Fig. 5).

\section{b) Local defects}

Concrete cracks were the most significant local defects observed, which frequently occured in girders or towers of bridges. Recently, it was reported that serious fatigue cracks have been found at steel slabs of some bridges.

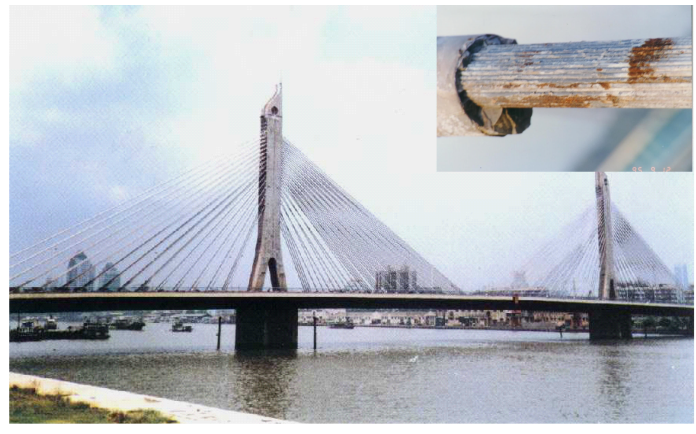

Fig.4 Broken stay cable due to corrosion of Haiyin Bridge.

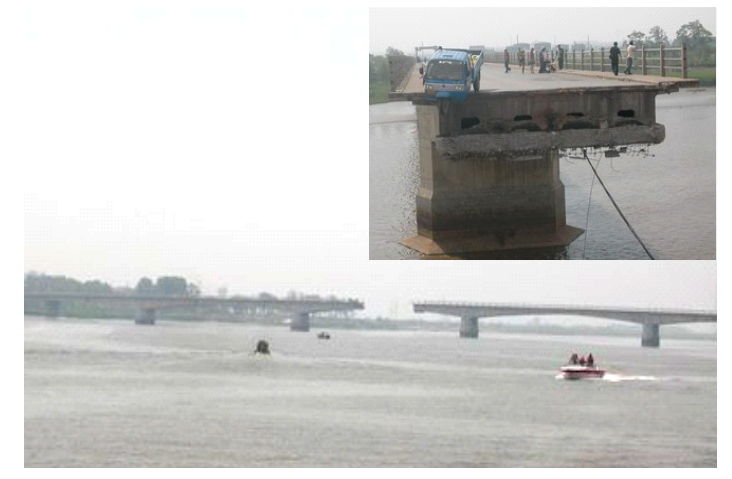

Fig.5 Fall down of Tian Zuang Tai Bridge in Liaoning Prov. due to broken of PC cables (2004).

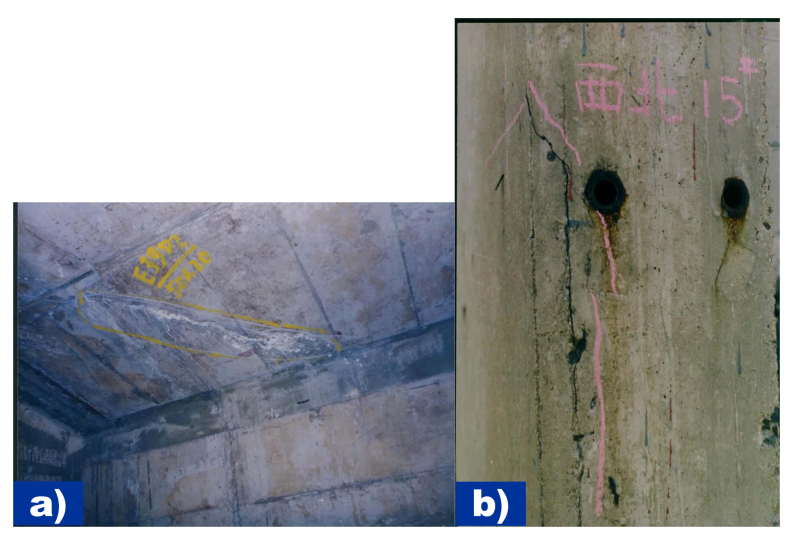

Fig.6 Cracks of concrete bridges. a) Cracks on top slab of box-girder, b) Concrete expansion on tower wall.

\section{c) Deterioration of non-structural components}

Non-structural components such as pavement, expansion joints, rainpipes etc. were heavily damaged. For example, Jiangyin Bridge, opened in 1999, where the pavement was replaced in 2003 due to the damage caused by overloading trucks.

These problems for bridges in operation can be ascribed to excess construction speed, imperfection of design code and unexpected increasing of traffic, under the background of rapid economic growth. Hence, it is significant to consider a SHMS for newly constructed long span bridges. 
Table1 Major cable-stayed bridge completed or under construction in China $(L>400 \mathrm{~m})$.

\begin{tabular}{|c|c|c|c|c|}
\hline & Bridge Name & Location & Main Span & Yr. of Completion ${ }^{1}$ \\
\hline 1 & Nanpu Bridge & Shanghai & $423 \mathrm{~m}$ & 1991 \\
\hline 2 & Yangpu Bridge & Shanghai & $602 \mathrm{~m}$ & 1994 \\
\hline 3 & Yunxian Bridge over Yangtze River & Hubei Prov. & $414 \mathrm{~m}$ & 1994 \\
\hline 4 & $2^{\text {nd }}$ Wuhan Bridge over Yangtze River & Hubei Prov. & $400 \mathrm{~m}$ & 1995 \\
\hline 5 & Tongling Bridge over Yangtze River & Anhui Prov. & $436 \mathrm{~m}$ & 1995 \\
\hline 6 & Xupu Bridge & Shanghai & $590 \mathrm{~m}$ & 1996 \\
\hline 7 & Lijiatou Bridge over Yangtze River & Chongqing & $444 \mathrm{~m}$ & 1997 \\
\hline 8 & Kap Shui Mun Bridge & Hangkong & $430 \mathrm{~m}$ & 1997 \\
\hline 9 & Ting Kau Bridge & Hongkong & $475 \mathrm{~m}$ & 1998 \\
\hline 10 & Shantou Queshi Bridge & Guangdong Prov. & $518 \mathrm{~m}$ & 1999 \\
\hline 11 & Baishazhou Bridge over Yangtze River & Hubei Prov. & $618 \mathrm{~m}$ & 2000 \\
\hline 12 & $2^{\text {nd }}$ Nanjing Bridge over Yangtze River & Jiangsu Prov. & $628 \mathrm{~m}$ & 2001 \\
\hline 13 & Qingzhou Bridge over Min River & Fujian Prov. & $605 \mathrm{~m}$ & 2001 \\
\hline 14 & Dafosi Bridge & Chongqing & $450 \mathrm{~m}$ & 2001 \\
\hline 15 & Jingsha Bridge over Yangtze River & Hubei Prov. & $500 \mathrm{~m}$ & 2002 \\
\hline 16 & Zhanjiang Bay Bridge & Guangdong Prov. & $480 \mathrm{~m}$ & 2002 \\
\hline 17 & Junshan Bridge over Yangtze River & Hubei Prov. & $460 \mathrm{~m}$ & 2002 \\
\hline 18 & Ehuang Bridge over Yangtze River & Huber Prov. & $480 \mathrm{~m}$ & 2002 \\
\hline 19 & Runyang Bridge $(\mathrm{N})$ over Yangtze River & Jiangsu Prov. & $406 \mathrm{~m}$ & 2003 \\
\hline 20 & Taoyaomen Bridge & Zhejiang Prov. & $580 \mathrm{~m}$ & 2003 \\
\hline 21 & Anqing Bridge over Yangtze River & Anhui Prov. & $510 \mathrm{~m}$ & 2004 \\
\hline 22 & $3^{\text {rd }}$ Nanjing Bridge over Yangtze River & Jiangsu Prov. & $648 \mathrm{~m}$ & 2005 \\
\hline 23 & Donghai Bridge (Navigation Span) & Shanghai & $420 \mathrm{~m}$ & 2005 \\
\hline 24 & Jintang Bridge & Zhejiang Prov. & $620 \mathrm{~m}$ & 2008 \\
\hline 25 & Sutong Bridge over Yangtze River & Jiangsu Prov. & $1088 \mathrm{~m}$ & 2008 \\
\hline 26 & Hangzhou Bay Bridge (Navigation Span) & Zhejiang Prov. & $448 \mathrm{~m}$ & 2008 \\
\hline 27 & Tianxingzhou Bridge over Yangtze River & Hubei Prov. & $504 \mathrm{~m}$ & u.c. \\
\hline 28 & Shanghai Bridge over Yangtze River & Shanghai & $730 \mathrm{~m}$ & u.c. \\
\hline 29 & Stongcutters Bridge & Hongkong & $1018 \mathrm{~m}$ & u.c. \\
\hline 30 & Fuling Shibangou Brigde over Yangtze River & Chongqing & $450 \mathrm{~m}$ & u.c. \\
\hline 31 & Minpu Bridge & Shanghai & $708 \mathrm{~m}$ & u.c. \\
\hline 32 & Xiangshan Bridge & Zhejiang & $688 \mathrm{~m}$ & u.c. \\
\hline 33 & Edong Bridge over Yangtze River & Hubei Prov. & $880 \mathrm{~m}$ & u.c. \\
\hline 34 & Jingyue Bridge over Yangtze River & Hubei Prov. & $816 \mathrm{~m}$ & u.c. \\
\hline 35 & Ningbo Bridge & Zhejiang Prov. & $464 \mathrm{~m}$ & u.c. \\
\hline
\end{tabular}

${ }^{1}$ u.c. $=$ under construction

\section{SHMS FOR LONG SPAN BRIDGES}

\section{(1) Objectives of SHMS}

Generally, the primary objectives of the development of SHMS for long span bridges are as follows: (1) To obtain comprehensive knowledge on the performance of a bridge, which is further used for assessing the structural safety, durability and serviceability; (2) To validate design assumptions and design loads, and to provide data for consummating the design code; and (3) To provide support for decision making on maintenance, repairs and management of bridge structures.

It is desired that a SHMS for bridges has the following functions: (1) Environmental conditions and physical and geometrical states (stress and deformation) of a bridge as well as mechanical behaviors of its key components can be monitored automatically in a real-time way. Also, the monitored data can be collected, stored and inquired according to requirement; (2) Structural condition can be tracked and abnormity of a bridge can be alarmed; (3) Static and dynamic 
Table2 Major suspension bridges completed or under construction in China $(L>400 \mathrm{~m})$.

\begin{tabular}{|c|c|c|c|c|}
\hline & Bridge Name & Location & Main Span & Yr. of Completion ${ }^{1}$ \\
\hline 1 & Dazi Bridge & Tibet Municipality & $500 \mathrm{~m}$ & 1984 \\
\hline 2 & Shantou Bay Bridge & Guangdong Prov. & $452 \mathrm{~m}$ & 1996 \\
\hline 3 & Xiling Bridge over Yangtze River & Sichuan Prov. & $900 \mathrm{~m}$ & 1996 \\
\hline 4 & Fengdu Bridge over Yangtze River & Sichuang Prov. & $500 \mathrm{~m}$ & 1996 \\
\hline 5 & Humen Bridge & Guangdong Prov. & $888 \mathrm{~m}$ & 1997 \\
\hline 6 & Tsingma Bridge & Hongkong & $1377 \mathrm{~m}$ & 1997 \\
\hline 7 & Jiangyin Bridge over Yangtze River & Jiangsu Prov. & $1385 \mathrm{~m}$ & 1999 \\
\hline 8 & Haicang Bridge & Fujian Prov. & $690 \mathrm{~m}$ & 1999 \\
\hline 9 & Yicang Bridge over Yangtze River & Hubei Prov. & $960 \mathrm{~m}$ & 2001 \\
\hline 10 & Zhongxiang Bridge over Yangtze River & Chongqing & $560 \mathrm{~m}$ & 2001 \\
\hline 11 & Egongyan Bridge & Chongqing & $600 \mathrm{~m}$ & 2001 \\
\hline 12 & $2^{\text {nd }}$ Wanxiang Bridge over Yangtze River & Chongqing & $580 \mathrm{~m}$ & 2004 \\
\hline 13 & Runyang Bridge (S) over Yangtze River & Jiangsu Prov. & $1490 \mathrm{~m}$ & 2004 \\
\hline 14 & Yangluo Bridge & Hubei Prov. & $1280 \mathrm{~m}$ & 2007 \\
\hline 15 & Siduhe Bridge & Hubei Prov. & $900 \mathrm{~m}$ & 2008 \\
\hline 16 & Huangpu Bridge & Guangdong Prov. & $1108 \mathrm{~m}$ & 2008 \\
\hline 17 & Xihoumen Bridge & Zhejiang Prov. & $1650 \mathrm{~m}$ & 2008 \\
\hline 18 & Beipanjiang Bridge & Guizhou Prov. & $888 \mathrm{~m}$ & u.c. \\
\hline 19 & Balinghe Bridge & Guizhou Prov. & $1088 \mathrm{~m}$ & u.c. \\
\hline 20 & Maanshan Bridge over Yangtze River & Anhui Prov. & $1080 \mathrm{~m}$ & u.c. \\
\hline 21 & Taizhou Bridge over Yangtze River & Jiangsu Prov. & $1080 \mathrm{~m}$ & u.c. \\
\hline 22 & Aizhai Bridge & Hunan Prov. & $1176 \mathrm{~m}$ & u.p. \\
\hline 23 & $4^{\text {th }}$ Nanjing Bridge over Yangtze River & Jiangsu Prov. & $1418 \mathrm{~m}$ & u.p. \\
\hline
\end{tabular}

${ }^{1}$ u.c. $=$ under construction; u.p. = under planning

Table3 Major arch bridges completed or under construction in China $(L>400 \mathrm{~m})$.

\begin{tabular}{l|l|l|c|c}
\hline & \multicolumn{1}{|c|}{ Bridge Name } & \multicolumn{1}{|c}{ Location } & Main Span & Yr. of Completion ${ }^{1}$ \\
\hline 1 & Wanxian Bridge & Sichuan Prov. & $420 \mathrm{~m}$ & 1997 \\
2 & Lupu Bridge & Shanghai & $550 \mathrm{~m}$ & 2003 \\
3 & Wushan Bridge & Sichuan Prov. & $460 \mathrm{~m}$ & 2005 \\
4 & Xinguang Bridge & Guangdong Prov. & $428 \mathrm{~m}$ & 2008 \\
5 & Caiyuanba Bridge & Chongqing Prov. & $420 \mathrm{~m}$ & 2008 \\
6 & Caotianmen Bridge & Chongqing Prov. & $552 \mathrm{~m}$ & u.c. \\
\hline
\end{tabular}

${ }^{1}$ u.c. $=$ under construction

safety, durability and serviceability of a bridge can be assessed and structural novelty can be identified; and (4) Data and graphs can be transmitted to specified parties.

The monitoring items are considered mainly based on the mechanical properties and the structural characteristics as well as the environmental condition of the bridge site. Consequently, the geometrical state and the static and dynamic responses of the bridge as well as the environmental and traffic conditions are determined to be monitored in SHMS. It is noted that the continuity and period of signal acquisition are different for various monitoring items. In general, the geometrical state and the static responses are monitored in a periodic fashion, while the structural dynamic responses and the environmental and traffic conditions are monitored continuously.

Bridge monitoring systems have been installed in some long span bridges in China and also around the world. However, it should be noted that current monitoring system by itself is far from the desired goal of lifecycle cost reduction. Existing instrumental techniques are limited, which makes it impossible to monitor all the critical regions in a structure related to 
the deterioration and safety of bridges. On the other hand, there still exists a gap between the measured data, though may be enormous in volume, and the condition and health assessment of bridges. Future attention should be focused on how to obtain information really concerning the deterioration and safety of structure and on how to use various information to improve the lifecycle performance of long span bridges.

\section{(2) Implementation of SHMS}

As show in Table 4, about 40 bridges in mainland and Hongkong of China ${ }^{6), 7), 8,99), 10), 11), 12), 13)}$ have been installed or will be installed with a SHMS, and most of them were implemented after 2000. During the first stage, the SHMS installed to the bridges in China were simple systems with limited number of sensors. After several years of operation of the system, some of them were upgrated according to the requirements of bridge management authorities. Recently, design and implementation of SHMS for a new bridge seems becoming a common practice. Almost all of long span bridges in China will have a SHMS.

The SHMS's lately designed or implemented represent the following trends: (1) Generally, a SHMS for a long span bridge consists of more than 50 sensors, and it takes about $0.2-2.0 \%$ of the total construction cost of the bridge; (2) Design concept of SHMS more emphasizes on the function to support maintenance and management of the bridge; (3) Durability of SHMS itself is concerned, and sensors and other hardwares are required to be replaceable and data can be continuously recorded when replacing hardwares; (4) Sensoring and data transmiting technologies that are not mature are prone to be rejected by bridge owners; (5) Some SHMS's are combined with monitoring system for construction control; and (6) Structural condition accessment are emphasized, and bridge engineering experts group as one of users of SHMS is included in the management personnel.

\section{RESEARCH AND DEVELOPMENT OF SENSING, TRANSMISSION AND SYS- TEM INTEGRATION TECHNOLOGY}

Some advanced sensing technologies, such as the fiber bragg grating (FBG) technology, the global positioning system (GPS) technology, the fatigue gauge, the electromagnetic (EM) sensor, and the acoustic emission (AE) technology, attract special attention recently in the mainland of China. The system integration technologies are also been investigated. This section gives a general review, which reflects the progress of sensing, transmission, and system integration technologies in China.

\section{(1) Fiber optic sensors}

\section{a) Research and development of FBG sensor}

The research and development on FBG technology for civil engineering structures in China are mainly carried out by Wuhan University of Technology, Nankai University, Tsinghua University, Harbin Institute of Technology, and Shanghai Institute of Optics and Fine Mechanics. Research topics include wavelength modulating method, encapsulation of FBG sensors, and adaptability of FBG when used for bridge structures.

For example, Zhao et al. ${ }^{14)}$ in 1996 experimentally used fiber optic sensors to detect internal stress of concrete structures. They embedded an optical fiber sensor in a concrete structure, the relationship between the optical fiber measurement and the internal state of concrete structure under compression and bending was investigated. The results showed that the embedded fiber optic sensing could monitor the internal stress state of concrete structure and the crack growth of concrete materials. Sun R. J. (2005) ${ }^{15)}$ evaluated the performance for FBG sensor, and the applicability of FBG in bridge structures was illustrated. Some new types of sensors based on FBG technology were developed, for example, Sun R. J. (2006) ${ }^{16)}$ developed an accelerometer for vibration measurement of bridges (Fig. 7).

\section{b) Application of FBG sensors}

In China, FBG sensors were first used in dam structures. In 2001, the stresses of a crane girder in a workshop building of Baoshan Steel Corperation in Shanghai were measured by installing more than 200 FBG sensors ${ }^{17)}$. It was reported that the performance of FGB sensors were better than traditional strain sensors. In 2002, Shenzhen Civic Center, a large span space structure, were monitored by FBG sensors. The system included 350 sensors in total for monitoring strains and temperatures of the steel components. In 2003, FBG sensors were adopted to monitor the strain variations of Lupu bridges in Shanghai. In SHMS

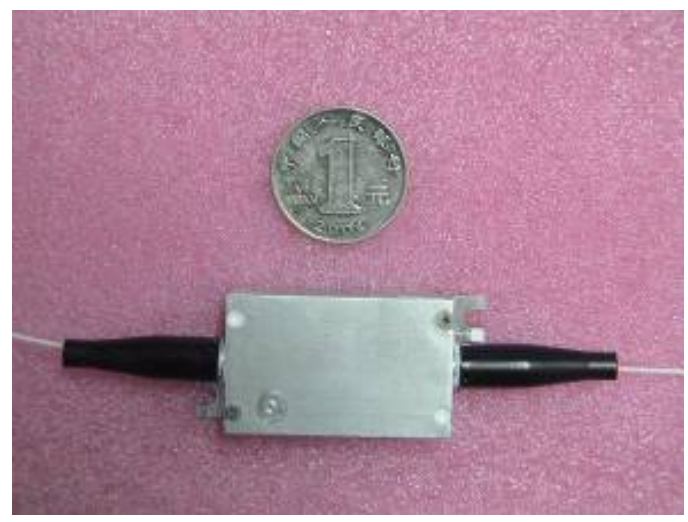

Fig.7 Accelerometer based on FBG sensor. 
Table4 Bridges with Structural Health Monitoring Systems in China.

\begin{tabular}{|c|c|c|c|c|c|c|c|c|c|c|c|c|c|c|c|c|c|}
\hline \multirow[b]{3}{*}{ No. } & \multirow{3}{*}{$\begin{array}{l}\text { Year of } \\
\text { compl. } \\
\text { (Year of } \\
\text { installation } \\
\text { of SHMS) }\end{array}$} & \multicolumn{2}{|c|}{ Bridge } & \multicolumn{14}{|c|}{ Number of primary sensors ${ }^{3}$} \\
\hline & & \multirow[b]{2}{*}{ Name } & \multirow[b]{2}{*}{$\begin{array}{l}\text { Style }^{2} \\
\text { (span: m) }\end{array}$} & \multicolumn{5}{|c|}{ Environment } & \multicolumn{8}{|c|}{ Response } & \multirow[b]{2}{*}{ Total $^{4}$} \\
\hline & & & & 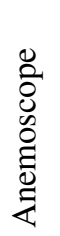 & 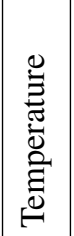 & 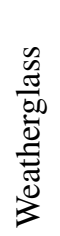 & 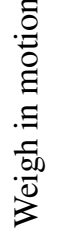 & 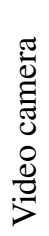 & 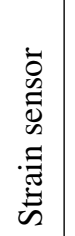 & 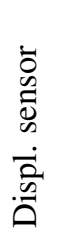 & 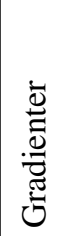 & $\begin{array}{l}\bar{\Phi} \\
\bar{\Xi} \\
\overline{0} \\
:\end{array}$ & ڤิ & 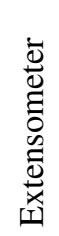 & 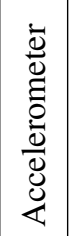 & 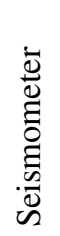 & \\
\hline 1 & 1968(u.k.) & $1^{\text {st }}$ Nanjing & $\mathrm{T}(160)$ & $\sqrt{ }$ & $\sqrt{ }$ & & $\sqrt{ }$ & & $\sqrt{ }$ & $\sqrt{ }$ & & & & & $\sqrt{ }$ & $\sqrt{ }$ & n.a. \\
\hline 2 & 1992(2005) & Dadu River & A & & & & & & $\sqrt{ }$ & & & & & & & & n.a. \\
\hline 3 & 1995(2002) & Tongling & $C(432)$ & 26 & 26 & & & & & & 30 & 12 & & & 116 & & 210 \\
\hline 4 & 1997(1999) & Xupu & $\mathrm{C}(590)$ & & 20 & & $\sqrt{ }$ & & 8 & & $\sqrt{ }$ & & & & 20 & & $>48$ \\
\hline 5 & 1997(1997) & Kap Shui Mun & $\mathrm{C}(430)$ & 2 & 224 & & 6 & & 46 & 6 & 5 & & 2 & & 2 & & 293 \\
\hline 6 & 1997(1997) & Tsingma & $\mathrm{S}(1377)$ & 6 & 115 & & 6 & $\sqrt{ }$ & 118 & 2 & 9 & & 14 & & 17 & & $>287$ \\
\hline 7 & 1998(1998) & Ting Kau & $\mathrm{C}(475)$ & 7 & 83 & & 6 & & 88 & 2 & & & 5 & & 45 & & 236 \\
\hline 8 & 1998(1998) & Humen & $\mathrm{S}(888)$ & & & & & & $\sqrt{ }$ & & $\sqrt{ }$ & $\sqrt{ }$ & $\sqrt{ }$ & & & & n.a. \\
\hline 9 & 1999(1999) & Jiangyin & $S(1385)$ & $\sqrt{ }$ & $\sqrt{ }$ & & & & $\sqrt{ }$ & $\sqrt{ }$ & & & $\sqrt{ }$ & & $\sqrt{ }$ & & n.a. \\
\hline 10 & $2000(2002)$ & Wuhu & $\mathrm{C}(312)$ & & $\sqrt{ }$ & & & & $\sqrt{ }$ & $\sqrt{ }$ & $\sqrt{ }$ & & & & $\sqrt{ }$ & & n.a. \\
\hline 11 & $2000(2000)$ & Hulan & CRF(40) & & $\sqrt{ }$ & & & & $\sqrt{ }$ & & & & & & & & n.a. \\
\hline 12 & 2001(2001) & Zhaobaoshan & $\mathrm{C}(258)$ & $\sqrt{ }$ & $\sqrt{ }$ & & & & $\sqrt{ }$ & $\sqrt{ }$ & & & $\sqrt{ }$ & & $\sqrt{ }$ & & n.a. \\
\hline 13 & $2001(2003)$ & Dafosi & $\mathrm{C}(450)$ & & $\sqrt{ }$ & & & & $\sqrt{ }$ & $\sqrt{ }$ & $\sqrt{ }$ & & & & $\sqrt{ }$ & & n.a. \\
\hline 14 & $2002(2001)$ & $2^{\text {nd }}$ Nanjing & $\mathrm{C}(268)$ & $\sqrt{ }$ & $\sqrt{ }$ & & $\sqrt{ }$ & & $\sqrt{ }$ & & & & & & $\sqrt{ }$ & $\sqrt{ }$ & n.a. \\
\hline 15 & 2002(2004) & Zhanjiang Bay & $\mathrm{C}(480)$ & $\sqrt{ }$ & $\sqrt{ }$ & & & & $\sqrt{ }$ & $\sqrt{ }$ & & $\sqrt{ }$ & $\sqrt{ }$ & & $\sqrt{ }$ & $\sqrt{ }$ & n.a. \\
\hline 16 & $2002(2002)$ & Niutoushan & $\mathrm{CRF}(42)$ & & $\sqrt{ }$ & & & & $\sqrt{ }$ & & & & & & & & n.a. \\
\hline 17 & 2003(2003) & Lupu & $\mathrm{A}(550)$ & & 100 & & & & 32 & $\sqrt{ }$ & & & & & 16 & & $>148$ \\
\hline 18 & 2004(2004) & Binzhou & $C(300)$ & $\sqrt{ }$ & $\sqrt{ }$ & & & & $\sqrt{ }$ & & & & $\sqrt{ }$ & & $\sqrt{ }$ & & n.a. \\
\hline 19 & $2004(2004)$ & Songhuajiang & $C(365)$ & $\sqrt{ }$ & $\sqrt{ }$ & & & & $\sqrt{ }$ & & & & $\sqrt{ }$ & & $\sqrt{ }$ & & n.a. \\
\hline 20 & $2004(2004)$ & Qianjiang & $\mathrm{A}(190)$ & $\sqrt{ }$ & $\sqrt{ }$ & & & & $\sqrt{ }$ & & & & & & $\sqrt{ }$ & & n.a. \\
\hline 21 & $2005(2005)$ & Donghai-1 & $\mathrm{CB}(50-160)$ & $\sqrt{ }$ & $\sqrt{ }$ & & & & $\sqrt{ }$ & & & $\sqrt{ }$ & $\sqrt{ }$ & $\sqrt{ }$ & $\sqrt{ }$ & & 270 \\
\hline 22 & $2005(2005)$ & Donghai-2 & $\mathrm{C}(420)$ & $\sqrt{ }$ & $\sqrt{ }$ & & & & $\sqrt{ }$ & & & $\sqrt{ }$ & $\sqrt{ }$ & $\sqrt{ }$ & $\sqrt{ }$ & & 190 \\
\hline 23 & $2005(2005)$ & Donghai-3 & $C(332)$ & $\sqrt{ }$ & $\sqrt{ }$ & & & & $\sqrt{ }$ & & & $\sqrt{ }$ & $\sqrt{ }$ & $\sqrt{ }$ & $\sqrt{ }$ & & 120 \\
\hline 24 & $2005(2005)$ & $3^{\text {rd }}$ Nanjing & $\mathrm{C}(648)$ & & & & & & $\sqrt{ }$ & $\sqrt{ }$ & & & & & & & n.a. \\
\hline 25 & $2005(2005)$ & Dongying & $\operatorname{CRF}(220)$ & & $\sqrt{ }$ & & & & $\sqrt{ }$ & & & & & & & & n.a. \\
\hline 26 & $2005(2004)$ & Runyang(S) & $S(1490)$ & $\sqrt{ }$ & $\sqrt{ }$ & & & & $\sqrt{ }$ & & & & $\sqrt{ }$ & & $\sqrt{ }$ & & n.a. \\
\hline 27 & 2005(2004) & unyang(N) & $\mathrm{C}(406)$ & $\sqrt{ }$ & $\sqrt{ }$ & & & & $\sqrt{ }$ & & & & $\sqrt{ }$ & & $\sqrt{ }$ & & n.a. \\
\hline 28 & $2008(2008)$ & Sutong & $\mathrm{C}(1088)$ & $\sqrt{ }$ & $\sqrt{ }$ & $\sqrt{ }$ & $\sqrt{ }$ & $\sqrt{ }$ & $\sqrt{ }$ & $\sqrt{ }$ & & $\sqrt{ }$ & $\sqrt{ }$ & & $\sqrt{ }$ & & n.a. \\
\hline 29 & $2008(2008)$ & Hangzhou Bay & $\mathrm{C}(448)$ & $\sqrt{ }$ & $\sqrt{ }$ & $\sqrt{ }$ & $\sqrt{ }$ & & 104 & & 41 & 4 & 11 & & 82 & & 260 \\
\hline 30 & u.c. & Stonecutters & $\mathrm{C}(1018)$ & $\sqrt{ }$ & $\sqrt{ }$ & $\sqrt{ }$ & $\sqrt{ }$ & $\sqrt{ }$ & $\sqrt{ }$ & $\sqrt{ }$ & & $\sqrt{ }$ & $\sqrt{ }$ & & $\sqrt{ }$ & & n.a. \\
\hline 31 & u.c. & Maocaojie & $\mathrm{A}(368)$ & $\sqrt{ }$ & $\sqrt{ }$ & & & & $\sqrt{ }$ & & & & & & $\sqrt{ }$ & & n.a. \\
\hline 32 & u.c. & Guangyangdao & CRF(200) & & $\sqrt{ }$ & & & & $\sqrt{ }$ & & & & & & & & n.a. \\
\hline 33 & u.c & Qingdao Bay-1 & $\mathrm{C}(260)$ & $\sqrt{ }$ & $\sqrt{ }$ & & & & $\sqrt{ }$ & $\sqrt{ }$ & & $\sqrt{ }$ & $\sqrt{ }$ & & $\sqrt{ }$ & & n.a. \\
\hline 34 & u.c & Qingdao Bay-2 & $C(120)$ & $\sqrt{ }$ & $\sqrt{ }$ & & & & $\sqrt{ }$ & $\sqrt{ }$ & & $\sqrt{ }$ & $\sqrt{ }$ & & $\sqrt{ }$ & & n.a. \\
\hline 35 & u.c & Qingdao Bay-3 & $S(260)$ & $\sqrt{ }$ & $\sqrt{ }$ & & & & $\sqrt{ }$ & $\sqrt{ }$ & & $\sqrt{ }$ & $\sqrt{ }$ & & $\sqrt{ }$ & & n.a. \\
\hline 36 & u.c. & Shanghai & $\mathrm{C}(730)$ & 5 & 54 & & & & 107 & $\sqrt{ }$ & & & 16 & & 14 & & $>196$ \\
\hline 37 & u.c. & Shenzhen WC & $\mathrm{C}(210)$ & $\sqrt{ }$ & $\sqrt{ }$ & $\sqrt{ }$ & $\sqrt{ }$ & $\sqrt{ }$ & $\sqrt{ }$ & $\sqrt{ }$ & & & $\sqrt{ }$ & & $\sqrt{ }$ & & n.a. \\
\hline 38 & u.c. & Minpu & $\mathrm{C}(708)$ & 2 & 62 & 1 & 14 & & 80 & & & 8 & 5 & 8 & 70 & & $>250$ \\
\hline
\end{tabular}

${ }^{1}$ u.k. = unknown; u.c. $=$ under construction;

${ }^{2} \mathrm{~T}=$ truss bridge; $\mathrm{A}=$ arch bridge; $\mathrm{C}=$ cable-stayed bridge; $\mathrm{S}=$ suspension bridge; $\mathrm{CRF}=$ continuous rigid-frame bridge; $\mathrm{CB}=$ continuous beam bridge;

${ }^{3} \sqrt{ }=$ monitored but the number of sensors is not clear; ${ }^{4}$ n.a. $=$ not available 

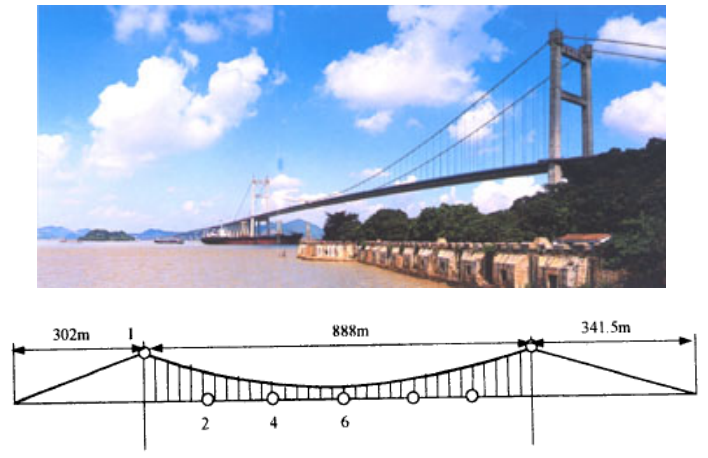

Fig.8 Humen Bridge and GPS measuring points.

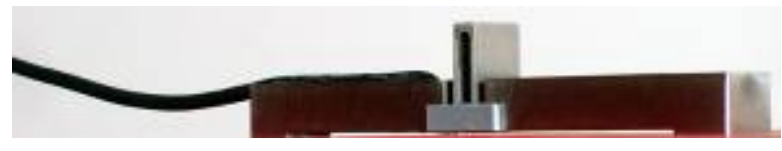

Fig.9 Fatigue Life Sensor.

of Donghai Bridge (Table 4), the FBG sensor techniques were used to measure the temperatures and strain of substructures from construction phase to operation phase.

As the maturation of FBG sensor technology, monitoring systems on infrastructures in China prefer to adopt this new technology. The design and installation specification for FBG sensors are also under discussion.

\section{(2) GPS}

GPS is a suitable technique for geometry monitoring of long span bridges. In recent years, some long span bridges have adopted GPS techniques in China $^{18), 19)}$. Humen Bridge in Guangdong province, a suspension bridge with a span of $888 \mathrm{~m}$, is the first long span bridge using GPS (Fig. 8). Traditional deformation measurement techniques are difficult to be used because of the long distance between the measured point to the reference point. The GPS sensors were also installed on the Tsing Ma Bridge, Kap Shui Mun Bridge and the Ting Kau Bridge in Hong Kong, as well as on Donghai Bridge, Sutong Bridge in the mainland China.

\section{(3) Fatigue Sensor}

Fatigue gauge can record the cycles of strain variation in steel specimens and automatically give an index related to fatigue damage magnitude. In SHMS of Donghai Bridge, fatigue sensors (Fig. 9) were developed based on the technique from aerospace industry. The strain level can be mechanically amplified for measurement by the sensor ${ }^{20)}$.

\section{(4) EM Sensor}

In 2004, Sun, B. N. ${ }^{21)}$ used the magnetoelastic (EM) sensors to monitor the tensile force of suspenders of 4th Qianjing Bridge (arch bridge). OVM Corp. developed an EM system for monitoring staycable or hanger systems.

\section{(5) AE Sensor}

Even though acoustic emission (AE) techniques have been reported to be used for monitoring main cables of suspension bridges, the research on damage identification technique based on AE signals are still lacking. $\mathrm{Jin}^{22)}$ reported the preliminary investigation, and the AE signals recorded from experiments for various pattern of material damage were analyzed using a wave propagation model and wavelet techniques.

\section{(6) Wireless Sensing Network}

Shi and $\mathrm{Shao}^{23)}$ developed a wireless sensing technology for low-frequency accelerometers based on the public wireless network. Each sensor can be connected to Internet through a General Packet Radio Service (GPRS) module. The real-time monitoring can be realized using these sensors. The operation parameters, such as sampling frequency, gain of amplifier, and frequency range of filter can be set remotely. The signals from various channels are synchronized by using a GPS clock. Therefore, multi-channels vibration measurement can be realized by using these wireless sensors in the area where the mobile communication network covered.

\section{(7) System integration and network design}

$\operatorname{Dan}^{24)}$ discussed the system integration schemes for intelligent health monitoring system of a civil/bridge structure. $\mathrm{Li}^{8)}$ studied the key technology and design method of a wireless sensing network for large-scale SHM. The frame and components of the system were proposed and tested in the laboratory. The wireless sensor network system for SHM was designed and constructed. The main works carried out included that: a novel system for large structure health monitoing was proposed based on wireless sensor network (WSN) technology; a data processing laboratory prototype was designed and developed based on the "Berkeley Mote" platform; a remoted data acquisition system was proposed based on the useage of the WSN and internet technology; a dynamic displacement monitoring system for bridge was developed to integrate the GPS technology, wireless system, high precise measurement engineering and data processing technology. 


\section{THEORETICAL DEVELOPMENTS}

As SHM is fundamentally a statistical pattern recognition process (Fig. 10), which involves three steps, data collection, signal processing, and condition assessment, the recent theoretical development in China is reviewed in these three aspects as follows.

\section{(1) Data collection}

Data collection is the first step in a SHMS. It involves determining the types and quantities of the sensors, the locations of the sensors, the types of data acquisition, storage and transmission hardware, and the data sampling frequency. Depending on the details of different cases, this step is really application oriented. For example, in some cases it may be adequate to collect data immediately after an extreme event. In some other cases, the data collections will be automatically performed every several hours to meet the requirement of long-term monitoring. As the novel sensing and data acquisition technologies are reviewed as a seperate topic, this section will focus on the recent development on optimal sensor placement. Cui et al. ${ }^{25)}$ offered a brief review on the optimal sensor placement algorithms. Based on the review, a methodology is provided for optimally placing sensors for a SHMS. The method starts with a small intuition set of measurement points. By making the mode shapes of interest as linearly independent as possible and making the measured kinetic energy optimizated, a reasonable additional set is figured out and the initial set is checked. Finally, by using the sensitivity analysis and Fisher information matrix, a more suitable set of sensor location can be determined for the monitoring of the critical parts of the bridge. Li et al. ${ }^{26}$ presented a technique to determine how to optimally place sensors for SHM system. Taking Tsing Ma Bridge as an example and using the genetic algorithms (GAs), they discussed the optimal placement of sensors on suspension bridges for the detection of accumulated damage. Liu et al. ${ }^{27)}$ proposed a method to optimize sensor locations for structural damage assessment based on the sensitivity study of mode shapes about structural stiffness changes. In terms of the contribution of the degree-offreedoms (DOFs), Fisher information matrix can be

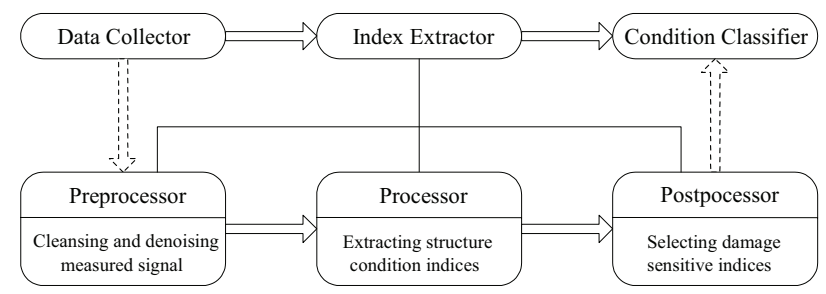

Fig.10 Flowchart of the signal-oriented SHM decomposed corresponding to each DOF. Each DOF is added to or subtracted from the sensor candidate set by calculated trace of every decomposed Fisher information matrix. The incomplete modes yielded from these optimized sensor locations are used to localize structural damage. Zuo et al. ${ }^{28)}$ compared several sensor placement techniques and concluded that the most applicable strategy in a SHM system is to empirically place the sensors according to the bridge style. Taking the off-diagonal element of Modal Assurance Criterion (MAC) matrix as the target function, Liu and Huang ${ }^{29)}$ proposed to obtain the optimal sensor locations by the reduced method. In addition, it is recommended that both the optimal result and economic benefit should be considered in sensor placement. Yu and Sun $^{30)}$ proposed to conduct structural vulnerability analysis during the process of determining sensor placement scheme for structural health monitoring. Based on a numerical study on the main navigation channel bridge of the Donghai Bridge, they suggested that sensors should be mounted on the components whose damage will induce unproportional structural damage as a priority.

\section{(2) Signal processing}

The extraction of discriminate condition indices from the SHM signal using some advanced signal processing tools is the step that receives much research attention in the SHM process. The kernel of this step is to process the SHM signal to extract some meaningful condition indices. The condensation ratio of a signal processing technique is very important because it will be advantageous and necessary particularly if comparisons of many data sets over the lifetime of the structure are envisioned. Because the data are generally acquired from a structure over an extended period and in an operational environment, robust signal processing techniques must retain sensitivity of the chosen indices to the structural changes of interest on the presence of environmental noise. In this section, some novel signal processing tools and the recent developed condition index are reviewed as follows.

\section{a) Signal processing techniques \\ Time domain techniques}

Since the SHM measurements are generally the time domain data, the techniques to extract useful features in this domain will induce no information loss and attract much attention. Liu et al. ${ }^{31)}$ offered a review on time domain modal analysis. In the paper the main time domain modal analysis methods are summarized. These methods are the stochastic subspace identification technique, the eigensystem realization algorithm, and the Prony technique. The important points for developing and application of time domain modal analysis are pointed out and the analysis re- 
sults of time domain and frequency domain in an example are compared. In accordance with the example, the main advantages of time domain modal analysis are without the knowledge of excitation force, and simultaneous identification of multi modes which are distributed crowdedly together. Fan et al. ${ }^{32}$ proposed an improved stochastic subspace identification technique for online condition monitoring and system evaluation. Based on the characteristics of stochastic subspace modal parameters identification method and the demands to parameter identification phase by condition evaluating work with online data acquisition system, a recursive approach creating Toeplitz matrix is proposed to decrease overlapped computation and shorten computation time. Satisfactory real-time property is shown in an application of the approach to process real world data from a monitoring system of Hong Kong Ting Kau Bridge under typhoon weather. Frequency domain techniques

After performing the Fourier Ttransform, the time domain signals can be transferred into the frequency domain as power spectra density function. Often these spectra densities are normalized by spectra of the measured force input. Some standard modal analysis procedures can then be applied to estimate the modal properties. Fan et al. ${ }^{33)}$ proposed an output only signal processing technique for bridge condition monitoring. In order to use the method online, a frequency domain system identification method, complex mode indicator function (CMIF) algorithm which is much easier to run automatically, is used to estimate modal parameters. The algorithm in this paper is verified by the field data from Ting Kau Bridge in Hong Kong. The results show that the method is reliable and useful in the bridge monitoring system design. Dan and $\operatorname{Sun}^{34)}$ derived a frequency domain multi-reference modal identification method based on the cross power spectra of the acceleration response under the unknown excitations. By applying it to the ASCE SHM benchmark problem, aided by the frequency average method, a good identification precision may be attained by this method.

\section{Time-frequency analysis}

In contrast to the Fourier analysis, the timefrequency analysis can be used to analyze any nonstationary events localized in time domain. The generally used time-frequency analysis tools are the short time Fourier transform (STFT), the Wigner-Vill (WV) transform, the wavelet transform (WT), and the Hilbert-Huang transform (HHT). Xu et al. ${ }^{35)}$ developed two schemes of time-frequency representations for the identification of the time-varying frequency of a single-degree-of -freedom system with changing stiffness. The STFT and the WV distribution are adopted. The simulated results indicated that those two tools are very effective for identifying time- varying modal parameters.

The amount of literature that uses the wavelet transform for damage detection is abundant. $\mathrm{Li}$ et al. ${ }^{36}$ ) made use of the multi-resolution characteristics provided by the WT for structural damage assessment. For a three-story RC frame model, it is found that obvious abrupt peak can be observed on the WT coefficient of the response measured at the damaged stories. $\mathrm{Li}$ and Suzuki ${ }^{37)}$ conducted the shaking table tests on a two-story wooden building and analyzed the experimental data using the WT. The results show that the WT can trace and detect the frequency degradation due to the structural damage. Ren et al. ${ }^{38)}$ analyzed the displacement of the damaged simplelysupported beam under sudden force and observed that the damage location can be estimated by the maximum of wavelet coefficients. Sun et al. ${ }^{39)}$ developed a WT based sub-structural identification technique for structural damage assessment. An experimental study on a three-story frame verified that the estimated element-level stiffness vector can be directly used for damage localization and quantification.

The Hilbert-Huang Transform is a novel data analysis technique and also receives much attention recently. Luo and $\mathrm{Shi}^{40)}$ applied the HHT method to make spectra analysis of seismic waves. The results verified that the HHT is an efficient method for the analysis of non-stationary data. Li et al. ${ }^{41)}$ studied the possibility of using the HHT to detect the damages in civil engineering structures. Based on the results of a simulation study, they concluded that the damage information could be extracted from the measured response using this method and the health conditions about the structure could be monitored reliably. Shi et al. ${ }^{42)}$ applied the HHT in structural damage detection by disposing model vibration table test data of Shenzhen commercial edifice. They concluded that the HHT based method can acutely determine natural frequency change under the different intensity of earthquake, and the Hilbert damping spectra can qualitatively display the evolution of damping loss factor during the period of earthquake.

\section{b) Condition index}

\section{Basic modal parameters}

The most common indices that are used in the vibration-based SHM are the common modal properties (resonant frequencies, damping ratios, and modeshape vectors). Liu et al. ${ }^{43)}$ reported an application of modal test in the damage identification of an old bridge in Guangzhou and verified that structural damage will induce the reduction of structural resonant frequencies. Zhang et al. ${ }^{44)}$ proposed to use the frequency graphs of the natural frequency to detect the occurrence and location of fault in concrete structure. Two natural frequencies of concrete cantilever beam in different situations are simulated with the finite el- 
ement program developed by Matlab. Results show that the damage parts of structure are identified by the graphs of frequency effectively and this approach could be used in practice.

Although the damping ratio also varies when damage occurs, its applications in damage assessment are quite few.

Damage assessment using mode shape vectors generally involves analyzing differences between the measured mode shape vectors before and after damage. Mode shape vectors are spatially distributed quantities; therefore, they provide information that can be used to locate damage. Wan et al. ${ }^{45)}$ presented the change ratio of the first order mode shape as the indicator for structure damage assessment. A numerical study on a cantilever beam verified its applicability and feasibility on the identification of the location and severity of a structural damage. Concerning that the displacement mode shape vector is insensitive to damage, some researchers proposed to use the stain mode shape vector as a replacement. Zhou and Shen ${ }^{46)}$ studied the theoretical principle and the technique of making use of the strain mode shape for structural damage assessment. From the test and analysis of concrete frames, it is verified that strain mode shape is more sensitive than displacement mode shape to damage in structures. Gu and Ding ${ }^{47)}$ applied a strain modal test to diagnose the position and degree of structural damage. Based on the test results of model beam in plaster, it is concluded that strain modes are very sensitive to non-node damage. The main constraint of this type of technique is large number of measurement locations are required to accurately characterize mode shape vectors and provide sufficient resolution for determining the damage location.

\section{Dynamically measured structural parameters}

Changes in the dynamically measured structural parameters (such as stiffness matrix, flexibility matrix and damping matrix) have also been used as damage sensitive indices. Among them, the most frequently used is the flexibility matrix. The flexibility matrix is defined as the inverse of the static stiffness matrix and relates the applied static force to the resulting structural displacement. Tang et al. ${ }^{48)}$ presented a methodology to localize the damage in structures only using the post-damage flexibility curvature. The damage location in structures can be identified without baseline modal parameters. The simulated cantilever beam and simply supported beam examples show that damage in structures can be detected with satisfactory precision using only a few of the lower frequency modes. $\mathrm{Ju}$ et al. ${ }^{49)}$ presented a method to diagnosis structural damage and fault using measured flexibility matrices. Using this method, the structural damage can be directly identified due to the linear relationship between the elements of flexibility matrix and the parameters of structural members. The flexibility method is very appealing for its less demand for modal parameters.

\section{Structural fingerprint response}

Structural fingerprint responses can be used as signature to represent structural systems and are regarded as a class of condition indices. Commonly used fingerprint responses include: (i) the time domain impulse response function (IRF); (ii) the frequency domain spectrum or power spectrum; and (iii) the frequency response function (FRF), which is a ratio between the response frequency spectrum (output) and the force frequency spectrum (input). Besides that, Sun and Chang ${ }^{50)}$ proposed a novel timefrequency domain condition index, wavelet packet signature (WPS), for the SHM purpose. The numerical study on a 5DOF system verified that this index is very damage-sensitive and noise-insensitive.

\section{Other index}

In addition to the condition indices mentioned above, some other indices also show their potential for damage assessment. Zong et al. ${ }^{51)}$ proposed to use the modal energy transfer ratios (ETR) as a parameter for bridge damage detection. A dynamic test on a 1:6 down scaled model highway-bridge was conducted in the lab and the ETR index is adopted to determine the damage location. The results show that ETR is a very sensitive damage signature for bearing damage and girder crack. It is more sensitive than the generally used resonant frequencies and damping ratios.

\section{(3) Damage assessment methods}

Damaged condition classification is another hot research focus in the SHM process. The main problem of this process is to find a classifier that is smart enough to distinguish whether index variability is due to structural physical condition change or due to normal measurement variations and then make a correct decision. The simplest classifier is to directly check the change of the measured indices (such as flexibility matrix and mode shape curvature) and then to predict damage location or severity directly ${ }^{52)}$. However, this kind of classifier is not always effective, especially for several kinds of indices (such as natural frequency and structural impulse response function). Hence, more powerful classifier is required. In this section, a review of damage assessment methods based on the dependency of analytical models is performed.

\section{a) Model-dependent methods}

According to the basic philosophy behind, the model-dependent damage assessment methods can be split into two categories: the methods based on inverse mapping techniques and the methods using artificial intelligent techniques.

\section{Inverse mapping methods}

Although the forward mapping from structural 
physical state (mass matrix, stiffness matrix and damping matrix) to condition index is normally derivable, the closed-form formula for inverse mapping is generally unavailable, especially for those structural systems with a large amount of DOFs. Liu et al. ${ }^{31)}$ theoretically deduced the relationship between structural eigen-frequency and damage location. On this basis, a new method of damage positioning is presented based on the change inspection of multiple orders of modal frequencies calculation results. It shows good effect when applying the method on a real steel beam.

Due to the difficulty in finding the closed form inverse mapping relationship, some researchers proposed to adopt sensitivity algorithms to solve the inverse problem. The problem is firstly approximated as a linear mapping from condition index residuals to structural physical parameter (normally stiffness of every element in a FEM model) perturbations according to the first-order Taylor series and the unknown changes in the structural physical parameters can be determined by either inverse derivation or constrained optimization. $\mathrm{Li}$ and $\mathrm{Liu}^{53)}$ presented a sensitivity analysis based structural damage identification methods. The method was proposed to locate the damage in beams. An illustrative example was given and the results verified the efficiency of the proposed method.

Optimal matrix updating techniques that seek to determine the system property matrices, such as the stiffness matrix, using the measured data are also used to find the inverse solution for structural damage assessment. These methods solve the inverse problem by forming a constrained optimization problem based on the structural equations of motion, the nominal model, and the measured data. Damage can then be detected, located and quantified by directly checking the difference between the updated matrices with the original matrices. Zhang et al. ${ }^{54)}$ proposed a damage detection technique for highway bridges based on the finite element model updating. Taking the analytical model of the structure under healthy state as the baseline, they proposed an iterative matrix norm minimization technique for the updating purpose. The updated variation of the stiffness matrix is regarded as due to damage. A numerical study on a cantilever beam verified the feasibility of the proposed technique.

\section{Artificial intelligent techniques based damage as- sessment}

With the fast development of the artificial intelligent techniques, their applications in SHM attract more and more research attention. Among these techniques, the neural network $(\mathrm{NN})$ classifier is the most popular tool for many applications ${ }^{55), 56), 57), 58), 59)}$. It owns both pattern matching and function mapping capability and is very powerful for SHM decision- making. The research focus is to reduce the computation complexity, improve the anti-interference capability and increase the learning efficiency. Sun et al. ${ }^{60)}$ presented a NN based technique for the damage localization of the deck of the cable-stayed Kap Shui Mun Bridge. Two kinds of networks, dynamic network and generic algorithm (GA) network, are investigated. Jiang et al ${ }^{59)}$ compared the performance of three probabilistic neural network (PNN) models on the detection of the damage location in a suspension bridge and proposed to use the principal component analysis PNN as it can shorten the training time and reduce the model size.

The fuzzy inference system, the fuzzy-NN classifier, and the fuzzy expert system are the second class of artificial intelligence (AI) based decision-making tools. Wang et al. ${ }^{61)}$ used the fuzzy theory to create comprehensive fuzzy system to assess bridge service property and set up an expert system for bridge assessment. Liu and Yuan ${ }^{62)}$ presented an approach for safety assessment of long-span concrete-filled tube arch bridge based on fuzzy-neural network. Dan and $\mathrm{Sun}^{34)}$ developed a recognition technology based on Mamdani fuzzy inference system for the SHM purpose. The recognition result shows that the technology developed in this paper takes a good prospect on building a SHM system based on language description.

Besides that, the genetic algorithms ${ }^{63)}$, the support vector machine ${ }^{33)}$ are also used for the SHM purpose.

\section{b) Model-free methods}

Due to the difficulty of analytical modeling and model updating, model-free methods attract more and more research attention recently. In this section, the most recent research developments on this topic are reviewed. The methods will be classified into two classes according to different levels of damage assessment that can be achieved.

\section{Model free damage occurrence detection methods}

The general procedure to detect structural damage in a model free way is to directly check the difference between the measured index and the baseline index or lump the difference into a quantity. If the change is greater than a preset threshold value, the damage alarming is produced. To determine the threshold value, different statistical models are adopted. Zhang ${ }^{44)}$ derived a probability-based measure, damage possibility, for structural novelty detection and damage localization. As illustrated in the case study on a 3-span-girder numerical model, the proposed approach is promising for online structural health monitoring. Sun and Chang ${ }^{64)}$ proposed a statistical wavelet based technique for structural degradation monitoring. Thresholds for damage alarming are established using the statistical properties and the one-sided confidence limit of the damage indicators 
from successive measurements.

\section{Model free damage localization methods}

To locate structural damage in a model free way, multiple sensors are required to evaluate the influence of damage to the responses at different position of the structure and mode shape function is a normal basis for further operation. Chang and Sun $^{65)}$ proposed to locate and quantify structural damage using spatial WPS. By checking the change of the spatial WPS curvature between the baseline intact beam and the damaged beam, the damage can be spatially located. Chen and $\mathrm{Yu}^{52)}$ used the changes in curvature mode shape to locate bridge damage. No analytical model is required to provide the baseline information. The baseline information can be obtained from the vibration test performed on the intact bridge.

\section{ISSUES IN FUTURE STUDIES}

The research topics related to structural health monitoring have become the hottest research area in civil engineering in China, since management and maintenance of infrastructures will gradually turn into the main societal demands after a construction rush of the country. The National Science Foundation of China has determined the structural health monitoring as one of the mostly supported research fields. The Chinese Ministry of Transportation and Communication has established several research projects aiming at the inspection, monitoring and maintenance of bridges. In the middle-long-term layout of the national science and technology research and development of China, which is issued by the Ministry of Science and Technology of China, the maintenance of infrastructures is emphasized and the financial support of the country will favor this area. The China Civil Engineering Society is establishing a special committee for structural health monitoring and maintenance to integrate and enhance the research and implementation of the related topics.

In the authors' opinion, more efforts have to be put into the following issues in the future:

(1) Design concept of SHMS implementation for a bridge has to be carefully considered. Generally, the cost of a SHMS will take about $0.2-2.0 \%$ of the total of construction cost of a bridge. The installation of SHMS will definitenly support the maintenance and management of the bridge.

(2) Vulnerability analysis of whole bridge system is necessary for the design of SHMS. The structural components that are easily to be damaged in the sense of causing safety, durability or serviceability problems of structures should be identified.

(3) Deformation measurement technology for long span bridges is lacking. The precision of GPS is not satisfied and the equipment is still expensive.
(4) Cable corrosion inspection and protection is a very important issue for the cable-stayed bridges and PC bridges.

(5) Fatigue sensing technology should be developed for monitoring the fatigue problems of steel bridge girders subjected to heavy traffic loads.

(6) Wireless sensing and data transmission are arrestive technologies. SHMS can be greatly improved with the development of these technologies.

(7) Durability of sensing and data transmission system is concerned seriously by bridge management authorities. Design lifetime for large span bridge is longer than 50 years even to 100 years. Therefore, a SHMS with comparative durability is required. Hardware with longer lifetime should be developed and the replacement of sensors and other hardware should be considered during the system design.

(8) System integration is important for implementation of SHMS. The compatibility and optimization of system should be investigated.

(9) Evaluation and assessment of structures based on SHMS still have a lot of unsolved research topics. With abundant monitoring data accumulated from the existing SHMS's for several years, many Chinese researchers are making great efforts to explore practice ways for structural evaluation.

(10) Design guideline or specification of SHMS has not been established yet in China.

ACKNOWLEDGMENTS: This study was partially supported by the Key Program of the National Natural Science Foundation of China (Grant No. 50538020), the National Key Basic Research and Development Program (Grant No. 2002CB412709), and the National High-tech R\&D Programs (863 Programs) (Grant No. 2006AA11Z120 and 2006AA11Z109). Special thanks to Prof. J. Z. Song and Prof. J. J. Shi, who offered valuable information on the recent large scale bridge projects and the related SHMS projects. The authors also wish to thank Mr. G. Yu and Miss. W. Hou for their assistances on references collection.

\section{REFERENCES}

1) Xiang, H. F. : China major bridge projects facing $21 \mathrm{st}$ century, Proc. of Intl. Conf. On Eng. \& Technological Science, Beijing, Oct., 2000.

2) Ge, Y. J., and Xiang, H. F. : Great demand and great challenge - Chinese major bridges under construction for improving traffic infrastructure nationwide -, Proc. of IABSE Symposium 2007, Weimar, Germany, Sept., 2007.

3) Wu, J. J., Chen, H., Zhang, Q. W., and Yuan, W. C. : Static load test of bridge coefficient of correction assessment of test, Highway, pp. 62-65, Dec., 2004 
(in Chinese).

4) Wu, H. J., Chen, A. R., Lu, P. : Typical damages and causes of bridges, Journal of Chongqing Jiaotong University, pp. 19-23, Dec., 2004 (in Chinese).

5) People Daily : 10 ${ }^{\text {th }}$ June, 2004 (in Chinese).

6) Ou, J. P. : Research and practice of intelligent health monitoring systems for civil ingrastructures in mainland China, Proc. of $3^{\text {rd }}$ China-Japan-US Symp. on Structural Health Monitoring and Control, CD-ROM, 2004.

7) Ou, J. P. : Some recent advances of intelligent health monitoring systems for civil infrastructures in mainland China, Proc. of Structural Health Monitoring and Intelligent Infrastructure, Tokyo, pp.131-144, 2003.

8) Li, H. W. : Research and Applications of Wireless Sensor Network Systems for Strucrural Health Monitoring. Doctoral Dissertation. Harbin Insititute of technology, pp. 1-180, Mar., 2005 (in Chinese).

9) Ko, J. M. : Shealth monitoring and intelligent control of cable-supported bridges, Proc. of Structural Health Monitoring and Intelligent Infrastructure, Tokyo, pp.51-64, 2003.

10) Wong, K. Y. : Recent developmetn of structural health monitoring system, Proc. of Intl. WS on Integrated Life-Cycle Management of Infrastructures, Hongkong, pp.238-261, 2004.

11) Headquarter of Donghai Bridge : Report of feasibility study on health monitoring system for Donghai Bridge, May, 2004 (in Chinese).

12) Headquarter of Sutong Bridge : Report of conceptual design of structural health monitoring system for $\mathrm{Su}-$ tong Bridge, Sept., 2003 (in Chinese).

13) Li, H. N., Gao, D. H., and Yi, T. H.: Advances in structural health monitoring systems in civil engineering, Advances in Mechanics, Vol. 39 (2), pp.152-166, 2008 (in Chinese).

14) Zhao, T. C., Huang, S. L., Chen, W. M., Tang, J., and $\mathrm{Fu}, \mathrm{Y}$. : Application on detecting of internal stress in concrete structure with fiber optic sensors, Piezoelectrics $\mathcal{F}$ Acoustooptics, Vol. 18 (6), pp. 394-399, Dec., 1996 (in Chinese).

15) Sun, R. J., Yan, X. F., Gong, J. Q., Sun, L. M., and Shi, J. J. : Development and implementation of FBG sensor for bridge SHM, SHMII'05, Nov., 2005.

16) Sun, R. J., Sun, Z., and Sun, L. M.: Design and Performance Tests of a FBG-Based Accelerometer for Structural Vibration Monitoring, Proc. of 4th ChinaJapan-USA Symp. on Struct. Cont. and Monitoring, Hangzhou, pp.450-451, 2005.

17) Gong, J. Q. : The investigation of techniques and application for the health monitoring of civil structures by fiber Bragg gratings sensors. Postdoctoral Report, Tongji University., Apr., 2005 (in Chinese).

18) Gou, J. J., Xu, L., and Jiang, J. J. : Online safety minitoring of long span bridge by GPS, Journal of GPS, Vol. 26 (4), pp. 2-8, 2001 (in Chinese).

19) Qiu, D. W., Yang, S. L., and Su, H. Y. : Design and surveying of long-span bridge GPS horizontal control network, Science of Surveying and Mapping, Vol. 29 (5), pp. 56-58, Oct., 2004 (in Chinese).

20) Sun, Y., Zhang, Q. W., and Hu, M. M.: Fatigue Estimation and Monitoring of Highway Steel Bridge
Structure, J. of Beijing Jiaotong University, 30 Supp., pp.68-72, 2006 (in Chinese).

21) Sun, B. N., Wu, X. P., Lou, W. J., Tan, Y. C., and $\mathrm{Yu}, \mathrm{J} . \mathrm{H}$. : The real time health monitoring system of Qianjiang 4th bridge, Environmental vibration: Prediction, Monitoring, and Evaluation, Edited by Chen Yunmin, Takemiya Hirokazu, pp. 420-424, 2003.

22) Jin, T., Sun, Z., and Sun, L. M.: Wave Propagation Modeling for Acoustic Emission Cable Monitoring, Proc. of 4th China-Japan-USA Symp. on Struct. Cont. and Monitoring, Hangzhou, pp.338-339, 2005.

23) Shi, J. J., Shao,Z. C., Zhou,G. J., and Sun, L. M. : Research on multi-channels wireless vibration sensors based on GPRS, Proc. of SHMII'05. Shenzhen, Nov., 2005.

24) Dan, D. H., Sun, L. M., and Xu, W. G. : Research on the software solution scheme of the intelligent civil/bridge structure. China-Japan Workshop on Vibration Control and Health Monitoring of Structures and Third Chinese Symposium on Structural Vibration Control, Shanghai, China, Dec., 2002 (in Chinese).

25) Cui, F., Yuan, W. C., and Shi, J. J. : Application of optimal sensor placement algorithms for health monitoring of bridges, Journal of Tongji University, Vol. 27 (2), pp. 165-169, 1999 (in Chinese).

26) Li, G., Qin, Q., and Dong, C. : Optimal placement of sensors for monitoring systems on suspension bridges using genetic algorithms, Engineering Mechanics, Vol. 17 (1), pp. 25-34, 2000 (in Chinese).

27) Liu, H., Qu, W. L., Yuan, R. Z. : Optimum sensor placement for structural damage detection based on sensitivity study, Earthquake Engineering and Engineering Vibration, Vol. 23 (6), pp. 85-90, 2003 (in Chinese).

28) Zuo, Y., Chen, M. X. and Zhao, Y. Y. : Health monitoring of bridges and optimal placement of sensor, Highway, Vol. 14, pp. 90-94, 2004 (in Chinese).

29) Liu, J. and Huang, W. P. : The reduced method of optimal sensor placement, The Ocean Engineering, Vol. 22 (1), pp. 32-36, 2004 (in Chinese).

30) Yu, G., Sun, Z.: Vulnerable component monitoring: a novel concept for health monitoring of complex structures, Proceeding of the Third International Conference on Structural Health Monitoring of Intelligent Infrastructures, Vancouver, Canada, November 14-18, 2007.

31) Liu, W. F., Liu, C. T., Ying, H. Q.: Research on damage orientation by change of eigenfrequency, Journal of Vibration and Shock, Vol. 23 (2), pp. 28-30, 2004 (in Chinese).

32) Fan, K. Q., Ni, Y. Q., Gao, Z. M. : Improved stochastic system identif ication approach with its application in bridge condition monitoring, China Journal of Highway and Transport, Vol. 17 (4), pp. 70-73, 2004 (in Chinese).

33) Fan, K. Q., Ni, Y. Q., Ko, J. M. : Bridge condition monitoring approach based on frequency domain system identification and support vector machine, Engineering Mechanics, Vol. 21 (5), pp. 25-30, 2004 (in Chinese).

34) Dan, D. H., Sun, L. M. : Modal identif ication based on cross power spectra density and its appl ication 
to ASCE SHM benchmark, Earthquake Engineering and Engineering Vibration, Vol. 24 (4), pp. 56-61, 2004 (in Chinese).

35) Xu, X. Z., Hua, H. X., Chen, Z. N. : Modal parameters identification using time-frequency analysis methods, Journal of Noise and Vibration Control, Vol. 5, pp. 3-7, 2002 (in Chinese).

36) Li, H. Q., Dong, L. g, Lv, X. L. : Identification of structural damage and test study based on wavelet transform, China Civil Engineering Journal, Vol. 36 (5), pp. 52-57, 2003 (in Chinese).

37) Li, S. J., Suzuki, Y. : Application of wavelet analysis to structural health monitoring, Journal of HUST (Urban Science Edition), Vol. 20, No. 2, pp. 32-35, Jun. 2003 (in Chinese).

38) Ren, Y. C., Lin, L., Ma, S. C. : Application of wavelet analysis in beam, Building Technique Development, Vol. 31 (2), pp. 8-9, 2004 (in Chinese).

39) Sun, Z., Chang, C. C., Sun, L. M. : Element level system identification for structural damage assessment, Proc. of the Second International Conference on Structural Health Monitering and Intelligent Infrastructure, 2005 (Accepted).

40) Luo, Q. F., Shi, C. X. : Hilbert-Huang transform and several problems in its calculation method, Journal of TongJi University, Vol. 31 (6), pp. 637-640, 2003 (in Chinese)

41) Li, S. J., Yu, H., Qu, W. L. : Structural damage detection by Hilbert-Huang transform, Journal of Wuhan University of Technology, Vo 1. 26 (8), pp. 44-47, 2004 (in Chinese).

42) Shi, C. X., Luo, Q. F., Shi, W. X. : Hilbert-Huang transform based approach for structural damage detection, Journal of TongJi University, Vol. 33 (1), pp. 16-20, 2005 (in Chinese).

43) Liu, J. J., Peng, Z. Y., Yang, T. C., Liu, J. T., Liu, C. H. : Applications of model test in bridge structure damage identification, J. of HUST (Urban Science Edition), Vol. 22, pp. 66-69, 2005 (in Chinese).

44) Zhang, D. L., Li, T., Sun, X. L. : Concrete structure fault diagnosis using natural frequency, Journal of Test and Measurement Technology, Vol. 17 (3), pp. 45, 2003 (in Chinese).

45) Wan, X. P., Li, X. C., Bao, K., Zhao, M. Y. : Structure damage diagnosis based on analyzing changes of vibration mode, Acta Aeronautica et Astronautica Sinica, Vol. 24 (5), pp. 422-426, 2003 (in Chinese).

46) Zhou, X. Y., Shen, P. S.: Study of damage assessment of concrete structures by strain model method, Journal of Hunan University, Vol. 24 (5), pp. 69-74, 1997 (in Chinese).

47) Gu, P. Y., Ding, W. N. : Application of modal test in diagnosing damage of beam, Journal of Vibration and Shock, Vol. 23 (3), pp. 60-63, 2004 (in Chinese).

48) Tang, X. B., Shen, C. W., Chen, D. F. : Flexibility curvature method in the damage detection of structures, Journal of Wuhan University of Technology, Vol. 23 (8), pp. 18-20, 2001 (in Chinese).

49) Ju, Y. Z. , Zhang, Z. J. ,Chen, J. Y., Wang, X. L. : Structural damage detection using measured flexibility method, Journal of Northeast China Institute of Electric Power Engineering, Vol. 24 (1), pp. 47-50, 2004 (in Chinese).
50) Sun, Z. and Chang, C. C. : Structural damage assessment based on wavelet packet transform, Journal of Structural Engineering, Vol. 128 (10), pp. 1354-1361, 2002.

51) Zong, Z. H., Huang, D. Z. and Wang, T. L. : Damage diagnosis of a steel-concrete composite bridge by ETR index, China Civil engineering Journal, Vol. 37 (5), pp. 59-69, 2004 (in Chinese).

52) Chen, H., Yu, D. J. : Study on the damage detection in the beam bridge using changes in curvature mode shape, Journal of highway and transportation research and development, Vol. 21 (10), pp. 55-57, 2004 (in Chinese).

53) Li, X. Y., Liu, J. K. : Damage identification of beams based on the vibration sensitivity analysis, Journal of South China University of Technology, Vol. 31, pp. 119-121, 2003 (in Chinese).

54) Zhang, Q. W., Yuan, W. C., Fan, L. C. : Damage assessment of highway bridges based on the model updating theory, EAST China Highway, Vol. 110, pp. 64-67, 1998 (in Chinese).

55) Lu, Q. B., Li, D. B., Zhang, W. : Neural network method in damage detection of structures by using parameters from modal test, Engineering Mechanics, Vol. 16 (1), pp. 35-42, 1999 (in Chinese).

56) Chen, J. L., Guo, X. L. : An experiment of a beam damage detection based on artificial network, Journal of Yantai University (Natural Science and Engineering Edition), Vol. 14 (3), pp. 217-223, 2001 (in Chinese).

57) Sun, Z. and Chang, C. C. : Wavelet packet signature: a novel structural health condition indicator, Proc. of Proceedings of the China-Japan Workshop on Vibration Control and Health Monitoring of Structures and Third Chinese Symposium on Structural Vibration Control, 2002.

58) Sheng, D. Q., Xu, L. H., Gong, J. W. : Identification of structure damage based on BP neural network, Journal of Wuhan University of Technology, Vol. 26 (9), pp. 48-50, 2004 (in Chinese).

59) Jiang, S. F., Yang, X. N., Chen, Z. C., Ni, Y. Q., Gao, Z. M. : Research on damage localization of principal component analysis based probabil istic neural network, Earthquake Engineering and Engineering Vibration, Vol. 24 (2), pp. 187-191, 2004 (in Chinese).

60) Sun, Z. G., Ko, J. M., Ni, Y. Q. : Identifiaction of damage location in bridge deck by neural network, Engineering Mechanics, Vol. 21 (1), pp. 42-47, 2004 (in Chinese).

61) Wang, Y. P., Zhang, B. Y., Zhang, S. R. : Expert system for comprehensive assessment to bridge service property using fuzzy theory, China Journal of Highway and Transport, Vol. 9 (2), pp. 62-67, 1996 (in Chinese).

62) Liu, M. Y., Yuan, W. G. : Research on safety assessment of long-span concrete-filled steel tube arch bridge based on fuzzy-neural network, China Journal of Highway and Transport, Vol. 17 (4), pp. 55-58, 2004 (in Chinese).

63) $\mathrm{Wu}, \mathrm{D} . \mathrm{H} .$, Zhao, R. D. : Research on the bridge health monitoring system based on genetic algorithms and neural network, Building Science Research of Sichuan, Vol. 28 (3), pp. 4-6, 2002 (in Chinese). 
64) Sun, Z. and Chang, C. C. : A statistical wavelet-based method for structural health monitoring, Journal of Struct. Engrg., ASCE, Vol. 130 (7), pp. 1055-1062, 2004.
65) Chang, C. C. and Sun, Z.: Locating and quantifying structure damage using spatial wavelet packet signature, Proc. of SPIE's 10th Annual International Symposium on Smart Structures and Materials, 2003.

(Received August 12, 2005) 